\title{
A Presença (ou Ausência) do Pensamento Marxista na Geografia Moderna
}

\author{
Astrogildo Luiz de França Filho
}

\begin{abstract}
Resumo
No cruzamento das Ciências Sociais com o marxismo, de maneira geral, a Geografia é identificada entre as últimas a estabelecer tal diálogo. Entre as várias hipóteses apresentadas para justificá-la está a de uma suposta negligência por parte de Marx para com os fenômenos espaciais. O objetivo deste trabalho é identificar, ao longo do final do século XIX e século $X X$, possíveis linhas de contato entre pensamento geográfico e pensamento marxista a fim de elucidar essa questão e, também, entender como a interação do materialismo histórico com a Geografia somente se inicia recentemente
\end{abstract}

Palavras-Chave: Geografia; Pensamento geográfico; Marxismo.

\begin{abstract}
In the crossing of Social Sciences with the marxism, in a generalized manner, Geography is identified enters the last ones to establish such dialogue. It enters some presented hypotheses to justify it is of a supposed recklessness on the part of Marx on the space phenomena. The objective of this work is to identify, throughout the end of century XIX and century XX, possible lines of contact between geographic thought and marxist thought in order to elucidate this question and, also, to understand as the interaction of the historical materialism with Geography is only initiated recently.
\end{abstract}

Keywords: Geography; Geographycal Thought; Marxism

\section{Introdução}

Tratar da relação entre a Geografia e o Marxismo num primeiro momento já abre margem para uma série de problemas, a começar pela própria adoção do termo marxismo, que por si já é controverso, uma vez que a história revela uma série de arbitrariedades na sua elaboração e em seu uso. ${ }^{1}$

Normalmente, quando um autor se propõe a realizar um exercício de 
leitura e reflexão sobre o marxismo, tende a sucumbir no equívoco de fazê-lo à luz do seu respectivo campo disciplinar, ou seja, o investigador se mostra tentado a "capturar" nos textos de Marx a presença de um "Marx filósofo", um "Marx sociólogo", um Marx "historiador" ou mesmo um Marx "geógrafo". O problema resultante deste tipo de abordagem está na incompatibilidade existente entre o pensamento de Marx, com sua visão totalizante da realidade, cuja ambição era compreender a essência dos problemas na sociedade de seu tempo, a fim de obter os subsídios científicos para a transformação da mesma através da ação política, e a atual visão compartimentada dos saberes, fruto da divisão do trabalho acadêmica. ${ }^{2}$ É inútil, portanto, tentar extrair da obra marxiana uma teoria geral do espaço, pois o resultado dessa insistência acarreta em uma compreensão distorcida, portanto, equivocada do pensamento de Marx.

Esse reconhecimento, porém, não nos impede absolutamente de afirmar a existência de um pensamento geográfico em Marx, muito ao contrário. É justamente evitando esse tipo de armadilha que estaremos aqui, traçando como objetivo deste trabalho, insistindo apenas na identificação, ao longo do século $X I X$ e $X X$, de possíveis linhas de tensão entre Geografia e Marxismo a fim de elucidar a suposta negligência por parte de Marx para com os fenômenos espaciais e, também, entender como a interação do materialismo histórico com a Geografia somente se inicia recentemente.

\section{Hegel, Marx e a Geografia: um caso de negligência?}

Tradicionalmente, nas pautas de debate que tem como pano de fundo este tema, um ponto que abre para polêmica diz respeito à acusação de alguns autores por um "desprezo" do marxismo em geral para com as questões de interesse espacial; segundo estes, desde Marx e Engels até os pensadores que o tem como base filosófica, há uma supremacia da História e da categoria tempo em detrimento da Geografia, colocada em um plano periférico. Nesse sentido é famosa a crítica vista a seguir:

"A pequena preocupação que Marx testemunha em relação aos problemas espaciais desaparece, com a formalização definitiva da crítica da economia política, tal como ela aparece no primeiro tomo de O Capital. Quanto mais Marx organiza o seu raciocínio com referência constante ao tempo (e a história foi encontrada reorganizada) mais ele se mostra indiferente aos problemas do espaço. Contudo, na qualidade de filósofo e fortemente influenciado por Hegel, ele não poderia ter deixado de estar consciente das relações estreitas que 
existem entre o tempo e o espaço" (Lacoste, 2003, pp. 140-141)

A observação acima é emblemática, pois se refere a um período da década de 70 onde, na França, tencionava-se exatamente esse tipo de articulação entre os dois saberes. Em parte, essa afirmação pode ser verdadeira, pois, como afirmamos acima, de fato não nos é possível ler Marx com vistas ao descobrimento de uma "teoria marxiana do espaço", ou uma "Geografia por Marx".

Entretanto, ao assumir essa posição de maneira intransigente, podem surgir interpretações distorcidas, equivocadas e até mesmo opostas às oferecidas pelo autor como, por exemplo, entender a relação entre Geografia e o pensamento marxista como algo incompatível, portanto, de um esforço desnecessário. Assim, a análise de Lacoste, a nosso ver, embora seja de grande relevância, padece de certo exagero que necessita ser mais bem esclarecido. Por outro lado, numa visão mais positiva, ela nos obriga a ter um olhar mais detido, tanto sobre as origens e transformações do pensamento geográfico, quanto para um acúmulo mais qualitativo da teoria marxista.

Para melhor buscar o entendimento acerca das interseções entre o pensamento geográfico e a pensamento filosófico nesse fin-de-siécle, uma leitura feita já há alguns anos atrás, nos apresenta uma proposta interessante de reflexão:

"E, finalmente, eu queria falar que em relação à situação do discurso teórico, respeito da geografia e marxismo, ou seja, a preocupação com o marxismo, surgiu recentemente. Dos estudos que eu tenho feito, a conclusão a que eu cheguei é a seguinte: - a Geografia, toda ela existente, essa positivista, tem, de um lado, raízes em Aristóteles, por causa da preocupação com a enumeração, classificação, tipologia, que é uma herança bastante antiga; e por outro lado tem raiz em Kant, com a preocupação de aparência e realidade. E a Geografia, ao chegar aos séculos XVIII e XIX, passa ao lado de Hegel, e não avança em direção à solução existencialista, que parte de Hegel, nem a solução marxista, que também parte de Hegel. Ela passa ao lado de Hegel, evita o problema da dialética, da contradição, se encontra com Comte e continua desenvolvendo sua tradição positivista. (...) Mas de qualquer maneira, a minha preocupação, aqui, é de mostrar que a Geografia fica alheia ao marxismo, durante muito tempo. E, aproximadamente nos últimos dez anos, no máximo, a Geografia passa a ter interesse em relação 
O motivo dessa citação extensa se explica pois nos permite destacar três questões que pensamos ser de nosso interesse aqui. Primo, que significado podemos atribuir a fala do autor ao afirmar que a Geografia "passa ao lado de Hegel'? Secundo, é possível, a partir daí, identificar pontos de contato no percurso do saber geográfico com o hegelianismo, e por sua vez com o pensamento marxista antes dos anos 70 do século XX? Tertio, por fim, é possível, a partir dessas questões já apontadas, entender como o se dá o aprofundamento tardio entre esses saberes? Estaremos apoiando nossa intervenção aqui com bases nestes pontos.

Se até o século XVIII, a Geografia era um tipo de conhecimento com tendências que iam desde o saber voltado para os eruditos até uma "geografia descritiva" que, para "alargar o círculo de seus auditores", se utilizava de relatos de viajantes misturados com pormenores políticos e até mesmo anedotas, ${ }^{3}$ para a maioria dos geógrafos de hoje, é consensual afirmar que, a partir dos trabalhos de Alexander von Humboldt e Karl Ritter é que são fundados os alicerces da chamada Geografia Moderna assim como, nestes autores, se localiza a influência filosófica de Humboldt e Ritter no pensamento de Immanuel Kant.

Entretanto, um exame mais apurado, utilizando como base o período histórico no qual ambos estão situados, revela que, muito embora 0 pensamento kantiano constitua-se como decisivo na formação de ambos e não seja equivocado apontá-lo como uma filiação direta, percebe-se também a presença de outras referências filosóficas também de suma importância. No pensamento humboldtiano, por exemplo, é nítida a presença direta dos intelectuais do idealismo alemão pós-kantiano, representado nas figuras de Schelling e Goethe e, em menor grau, de Schiller. ${ }^{4}$

A presença hegeliana, normalmente associada a Ritter, também pode ser encontrada em Humboldt que chegou a travar contato direto com o filósofo em meio às suas visitas a Jena, onde Hegel lecionou e desenvolveu boa parte de sua obra, muito embora seja reconhecida sua relevância menor em relação aos demais autores. Na sua obra máxima O Cosmos, Humboldt faz uma citação direta de maior representante do idealismo alemão:

"Os fenômenos exteriores, coloca Hegel em sua Filosofia da História, são de alguma forma traduzidos em nossas representações internas. O mundo objetivo, pensado por nós, em nós refletido, está submetido a formas eternas e necessárias de nosso ser intelectual. A atividade do espírito se exerce sobre os elementos que the são fornecidos pela observação sensivel". (Humboldt apud Moraes: 1983, p. 142) 
Em Ritter, por sua vez, encontramos, de forma geral, as mesmas bases de influência filosófica vistas em Humboldt: o idealismo pós-kantiano alemão do final do século XVIII. Entretanto, admite-se uma ligação muito mais direta de Hegel com Ritter do que com Humboldt, uma vez que ambos frequentaram por bastante tempo o mesmo espaço da Universidade de Berlim (em que Hegel chegou a ser reitor) onde os dois encontravam-se entre os notáveis da época, apesar de suas diferenças político-ideológicas. ${ }^{5} \mathrm{Um}$ fator decisivo que exprime a relação de conhecimento entre os dois está no fato de, ao contrário do exemplo anterior de Humboldt, Hegel citar Ritter abertamente em suas Lições sobre a Filosofia da História Universal:

"Ritter é quem melhor compreendeu e expressou as diferenças entre estas três partes (referindo-se aos continents africano, asiático e europeu). Nele encontramos sugestões engenhosas referentes ao nexo da evolução histórica posterior." (Hegel apud Moraes: 1983, pp. 228-229)

Ainda conforme Moraes, em uma primeira leitura é possível encontrar em ambos correspondências entre as concepções de "totalidade", "unidade", "particularidade", "espírito (ou caráter) dos povos e "terra como teatro da história", encontradas entre os dois autores. Em suas "Lições sobre a Filosofia da História", Hegel incorpora diversos postulados para interpretação geoquímica extraídos da obra de Ritter como sua perspectiva acerca dos continentes como "indivíduos geográficos"; a importância fundamental da relação entre formas sólidas e entre formas fluidas, ou seja, os continentes e os mares; a relevância histórico-cartográfica da relação entre oriente e ocidente e a correlação entre grau de dependência da natureza e grau de civilização.

A partir desses elementos colhidos da "Erdkunde" de Ritter, Hegel desenvolveu sua filosofia da história, definindo-a como "o movimento do espírito", ou seja, a história de como o "espírito" evolui a partir de suas formações exteriores, ou seja, a formação das sociedades dos povos, sob essa diferenciação do espírito consonante com as diferenças entre os povos que, por sua vez, está ancorada numa base geográfica.

Desta forma, se para nós é clara e evidente a ligação filosófica de Humboldt e Ritter com o pensamento kantiano, também nos é possível estabelecer um elo com Hegel, apesar de não podermos aqui identificar com clareza quais os pontos exatos da filosofia hegeliana presente nos dois autores. Queremos, contudo, apontar que, à revelia do discurso tradicional sobre os dois formadores da Geografia Moderna, a consolidação do saber geográfico enquanto ciência se dará com a influência de outras matrizes filosóficas, conforme assinalado em seguida por Santos: 
Ratzel e mesmo nos trabalhos de Ritter. (...) Todavia, e por múltiplas razões, foi a herança idealista e positivista que, afinal de contas, acabou por se impor à geografia, isto é, à geografia oficial: o cartesianismo, o comtismo e o kantismo eram frequentemente apoiados e misturados aos princípios de Newton e também ao darwinismo e ao spencerismo. (Santos: 2002, p. 46)

Nesse sentido, um argumento bastante plausível colocado por Quaini baseia-se que, nos casos dos autores que normalmente simplificam sua ligação direta com Kant, uma explicação seria o fato de que estes "preferiram a de Kant-Humboldt, deixando quase que totalmente à margem a de Ritter-Hegel, provavelmente porque esta última teria obrigado os geógrafos a entrar em

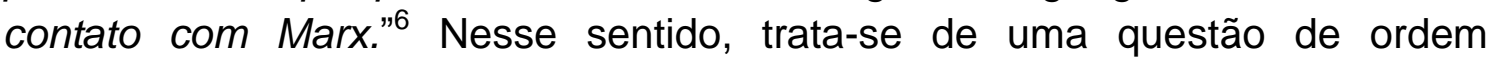
historiográfica, uma vez que envolve a construção de uma narrativa.

Para Hegel, o saber geográfico tem um significado muito diferente da perspectiva kantiana, pois permite entender a dualidade do homem enquanto ser natural e sujeito da história. Assim a Geografia aparece como uma chave para a compreensão do mundo, na medida em que permite entender as diversas possibilidades que 0 ambiente oferece aos povos nas diversas regiões da terra. Não à toa, para Marx, Hegel é o primeiro a compreender "o autoproduzir-se do homem como um processo", o homem como fruto do seu trabalho. Entretanto, essa visão geográfica apresentada nas Lições sobre a Filosofia da História está preocupada basicamente apenas em entender as diferentes maneiras pelas quais o "espírito" encarna nas diferentes porções da superfície terrestre que, pelas múltiplas possibilidades que o ambiente oferece, terminam por resultar em mero "lastro natural" para a "corporificação" desse mesmo "espírito".

Ou seja, a Geografia em Hegel reduz-se a uma etnologia, apoiada em uma concepção determinista de civilização, camuflada sob uma roupagem geográfica onde a superfície terrestre, na verdade, serve de substrato para ratificar a filosofia idealista, onde "mesmo os fatos geográficos mais 'terrestres' vinham transfigurados no céu da idéia". Para SOJA, há aqui um problema fundamental advindo do hegelianismo que será desdobrado mais adiante no materialismo histórico quando Marx fizer a crítica, a negação e a inversão do sistema hegeliano:

"Assim, colocar a dialética hegeliana 'de pé' foi uma negação do idealismo e uma rejeição específica do fetichismo territorial ou espacial, uma hermenêutica em que a história era determinada por uma consciência espacial inatamente dada, quer se concentrasse no Estado, no nacionalismo cultural, no regionalismo ou no coletivismo local. (...) As inversões marxistas foram 
usadas para forçar o abandon das influências hegelianas na virada do século, inclusive na Alemanha, e implantaram um antiespacialsmo teórico e político ameaçador. A expansão inicial do marxismo na França, entretanto, coincidiu com um grande reflorescimento hegeliano, um reinvestimento que trouxe consigo uma sensibilidade menos expurgada para a espacialidade da vida social." (Soja: 1993, p. 61)

Assim a crítica de Lacoste necessita ser reconsiderada ao identificar essa suposta ausência das questões envolvendo o espaço em Marx, por não apresentar questões que só aparecerão mais tarde, como resultado das leituras de geógrafos da obra de Marx, e que nos permitiriam identificar outras sutilezas por detrás dessa suposta negatividade de Marx para com o espaço.

\section{A Geografia Clássica em meio a expansão do marxismo na Europa}

O ano de 1859 é de grande relevância na história do pensamento ocidental, pois, num intervalo de poucos meses, morrem os fundadores da Geografia Moderna, Humboldt e Ritter, além da publicação quase que simultânea de $A$ origem das espécies de Charles Darwin e Para a Crítica da Economia Política de Karl Marx, uma antecessão de sua obra máxima $O$ Capital.

Em meados de 1883, ano da morte de Marx, se tem início o processo de difusão de seu pensamento, com Engels ainda vivo numa atividade que Ihe ocuparia seus últimos doze anos de vida, e continuada pela geração da chamada II Internacional, centrada nas figuras de Karl Kautsky e Eduard Bernstein. O resultado foi, apesar do ritmo lento e gradativo, que ao final de aproximadamente de duas décadas, temos a afirmação e o espraiamento da influência de Marx por praticamente todo o continente europeu, além de várias outras partes do mundo. ${ }^{8}$

"Se no momento da morte de Marx essa influência era muito escassa, principalmente porque Marx era pouco conhecido e pouco lido fora dos círculos da intelligentsia da Europa oriental, por volta de 1914 ela já tinha se tornado bastante grande. Em vastas regiões da Europa, eram poucas as pessoas cultas que ignoravam sua existência; e alguns aspectos da sua teoria já tinham se tornado de domínio público." (Hobsbawn: 1982, p. 111)

Ao chegar no período da Primeira Guerra Mundial (1914-1918), o 
pensamento marxista havia encontrado larga exposição não apenas nos círculos operários e nos movimentos revolucionários, mas também no ambiente acadêmico, muito embora houvesse ainda uma forte resistência não ao Marx em si, mas quaisquer temáticas ou doutrinas que possuíssem alguma vinculação política ao socialismo.

Nesse sentido, há um ponto curioso a ser observado: a resistência dos franceses a Marx e aos marxistas no período pré-primeira guerra. Dentre as motivações mais prováveis para essa demora dos franceses na divulgação interna do pensamento marxista em seu país, podemos destacar a já antiga tradição socialista, presente inclusive na formação política de Marx que não desconhecia nomes que iam desde Rousseau até Saint-Simon. Na virada do século, as idéias do chamado socialismo utópico francês já haviam, inclusive, penetrado na academia, portanto, não é de admirar a presença tardia do pensamento marxista nesse ambiente, uma vez que haviam divergências políticas com o socialismo de Marx. Na academia francesa, o nicho mais receptível a essas idéias se encontrava nas ciências sociais, leia-se no campo da Sociologia.

"Mencione-se, contudo, a fraqueza notável, se bem que não surpreendente, da presença marxista na França. Embora os ambientes da sociologia francesa, fortemente republicanos e "dreyfusards", tendessem à esquerda, e muitos colaboradores jovens da revista Année sociologique tenham se tornado socialistas, uma certa influência marxista (bastante discutível) só poderia ser reconhecida - e mesmo assim, depois de 1914 - no caso de Hallbwachs (1877-1945)." (Hobsbawn: 1982, p. 107)

Por outro lado, os historiadores oficiais, seja na França ou na Alemanha, buscavam de todas as formas evitar quaisquer tipo de mudanças que afetassem sua concepção tradicional da História. Nesse sentido, a resistência ao corpo teórico-metodológico proveniente da visão marxista da história caracterizava uma defesa "não só contra a social-democracia e a revolução como contra as ciências sociais, em geral. (...) Portanto, o inimigo não era só Marx, mas qualquer invasão das ciências sociais no campo histórico."

Outro ponto importante que não deve ser ignorado é o fato dos textos de peso metodológico mais importantes de Marx - os Grundrisse, A ldeologia Alemã, os Manuscritos Econômico-Filosóficos de 1844, entre outros começarem a ser publicados e difundidos apenas durante o período entre guerras do século XX. Este é um ponto de grande importância para compreendermos tanto a relação da Geografia com o marxismo neste período quanto para entender o próprio interesse das ciências sociais daquele tempo, do marxismo como método científico, mesmo apesar das intransigências do

TAMOIOS. ANO V. № 1, 2009 - ISSN 1980-4490 
"marxismo-leninismo" soviético. Significa compreender que é basicamente na década de $30 \mathrm{em}$ diante, onde o marxismo, visto como referência teóricometodológica, passa a ser reconhecido e assimilado, pouco a pouco, pelas ciências sociais na França.

Diante de tudo isso, não é de se estranhar uma ausência aparente de referências ao marxismo nos textos clássicos franceses. Nos Princípios de Geografia Humana de Vidal de La Blache, não se observa qualquer menção ou referência direta a Marx. Também não se conhece literatura que comprove conexão ou mesmo conhecimento por parte de La Blache para com 0 marxismo que possa afirmar essa hipótese.

Apesar disso tudo, em Santos: 2002, p. 51, ao comentar das referências filosóficas presentes na gênese da Geografia Francesa e Anglosaxã, admite já nos trabalhos da época "uma filiação direta com os trabalhos de Marx e dos marxistas". Para além de tudo isso, chega a afirmar que, ao inspirar-se nos estudos de Marx para entender o processo histórico da organização geográfica entre o feudalismo e o capitalismo, "os fundadores da geografia moderna utilizaram uma metodologia congelada, pecaram por dogmatismo e sobretudo consagraram um erro de interpretação que desgraçadamente perdura até hoje". ${ }^{10}$

O momento mais aparente de afinação do pensamento marxista com a Geografia nesse período aparece em Jean Brunhes, segundo Moreira (2008) o maior responsável pela introdução do pensamento dialético na Geografia. Tal opinião também compartilhada por Santos.

"E Jean Brunhes? Ao lê-lo, fica-se atônito com a similitude de tantas de suas formulações com as idéias marxistas. O espanto só é menor pelo fato, já realçado, de que, em seu afã de acreditar a geografia como ciência, alguns dos fundadores se sentiram atraídos pelo positivismo, onde eles buscavam inspiração e conforto."

(Santos: idem, p. 53)

Seja como for, essa entrada ainda é notadamente incipiente nesse momento do pensamento geográfico, situação que só irá se modificar anos depois. ${ }^{11}$

\section{O marxismo na Geografia Ativa e na Renovação}

A geografia que busca sua inspiração no marxismo tem seu desenvolvimento a partir dos países anglo-saxônicos, mas o cenário inicial surge, de fato, na Geografia Francesa e, de acordo com Soja "refletiram a 
centralidade peculiar que o espaço havia reassumido nas tradições intelectuais francesas do século XX. Uma explicação parcial para essa centralidade singular, especialmente na esquerda, pode ser encontrada na história do marxismo francês" (Soja: 1993, pp, 59-60).

Nos anos 50 e 60, na França, havia acontecido um forte debate interno sobre a relevância e a aplicação da Geografia, sobretudo em relação ao planejamento, onde a chamada Geografia Aplicada, preconizada por Michel Phlipponneau e outros, permitiu um debate que atentava para uma questão fundamental: a idéia de que os geógrafos não seriam aqueles que iriam propor e executar o planejamento territorial, mas outros círculos formados por burocratas ligados ao Estado.

Como oposição a essa tendência surgiu um grupo de geógrafos, donde se destacou o nome de Pierre George. Algumas de suas reflexões centrais estão contidas no livro A Geografia Ativa, publicado originalmente em 1964, do qual foram co-autores Raymond Guglielmo, Yves Lacoste e Bernard Kayser. Entretanto, mais que o próprio livro, porém, esta posição formada por esses geógrafos acabou por associar-se praticamente a todo um conjunto de pesquisas geográficas. (Bomfim: 2007)

Para Bomfim, as discussões levantadas por esses autores, que iam desde temas sobre subdesenvolvimento até 0 planejamento urbano, possibilitaram a sua inserção e adoção, no Brasil, de duas formas até certo ponto antagônicas: de um lado, foram recebidas como "propostas metodológicas relacionadas à regionalização do espaço, sobretudo pelo IBGE" e por profissionais de atuação focada basicamente em questões técnicas; por outro lado, também foram "aceitas como um conjunto de proposições de uma geografia "à esquerda"; engajada". 12

Assim, pois, essa Geografia Ativa tem uma dupla face onde, ao mesmo tempo, que há uma postura política de esquerda, haja vista o engajamento de seus atores ao Partido Comunista Francês (PCF), mantém-se uma continuidade teórica, dada a postura basicamente a-crítica em relação à herança da geografia vidaliana.

"[o] pensamento de Pierre George pode ser interpretado como um resultado muito elaborado [...] de pressupostos da reflexão possibilista. Entre outras coisas, porque é uma reflexão essencialmente empirista, que raramente explicita seus pressupostos epistemológicos, antológicos e metodológicos. [Assume o autor] a inspiração lablachiana e a continuidade dos fundamentos da 'escola francesa' [e] esta filiação transparece claramente na total acriticidade com relação a seus antecessores, [sendo] como se uma geografia anteriormente apolítica passasse a manter uma postura militante." (Escolar e Moraes apud Bomfim, idem, p. 99) 
Dessa maneira, encontra-se na postura de Pierre George, contraditoriamente, uma defesa da neutralidade científica exercida paralelamente com o engajamento político e com a crítica a um discurso geográfico comprometido com o Estado; ou seja, uma ofensiva ao utilitarismo na geografia, em função de uma posição política na qual o marxismo fora incorporado de maneira "essencialmente prática" ao conhecimento geográfico. ${ }^{13}$ O caso da filiação de Pierre George ao PCF ocorrera dentro de um determinado contexto, após a $2^{-}$Guerra Mundial, onde se adotara uma linha política de formação de quadros do partido cuja organização era baseada em especialidades profissionais, assim, havia uma "célula de geógrafos", que realizou um encontro - o chamado Seminário de Ivry - "para debater formas de incrementar uma militância na disciplina". Mas esse grupo de geógrafos que entrava no partido tinha muito mais o objetivo de coletar informações sobre as regiões francesas para o mesmo, que ajudar a promover uma discussão teórico-metodológica sobre o marxismo. Ou seja, a aproximação dos geógrafos de formação clássica aos fundamentos marxistas está muito mais ligada a uma demanda prática do que resultado de uma construção teórica. ${ }^{14}$

À explícita identificação da geografia aos métodos empíricos e positivistas, Bomfim defende a continuidade com a escola francesa, a qual ganharia ares progressistas, pois, presumivelmente oposta ao quantitativismo, associado de maneira apressada, por sua vez, ao autoritarismo.

"Para tornar mais claro: reconhecida a percepção das limitações da geografia quantitativa e seu corolário, o planejamento - cujos resultados, em meados dos anos 70, pareciam pouco satisfatórios -, tratava-se de buscar na Geografia Ativa, um referencial crítico, cujas ligações com o marxismo, porém, estavam descoladas da reflexão geográfica, sendo, pois, resultados de opções políticas."

(Bomfim: 2007, p. 107)

Entretanto, no final dos anos 60, a França apresentava uma outra conjuntura caracterizada por uma intensa mobilização política. Dada as condições específicas que culminaram no movimento de maio de 68 , aqui destacadas a crise da universidade e a amplitude do movimento estudantil e operário franceses, no início da década seguinte ainda se viam resultados dessas repercussões na sociedade, em especial na comunidade acadêmica. Todos esses eventos aconteciam em meio a crise do neopositivismo e da Nova Geografia.

Entretanto, o sinal para a guinada da geografia francesa só começa de fato em 1973 com a publicação do volume da História da Filosofia dedicado à Filosofia das Ciências Sociais onde o organizador François Châtelet deixa a cargo de Yves Lacoste o capítulo sobre Geografia. O texto de Lacoste provoca um balburdio sem precedentes na comunidade geográfica francesa na medida

TAMOIOS. ANO V. № 1, 2009 - ISSN 1980-4.490 
em que denuncia a crise na qual a Geografia se encontra instaurada. Nesse clima de receptividade, aparece a obra mais representativa deste período: $A$ Geografia, isto serve, em primeiro lugar, para fazer a guerra", onde denuncia a existência de uma geografia escolar de atitude e formação extremamente alienantes e de uma geografia dos estados maiores de caráter estratégico e político utilizada pelos Estados-Nacionais. ${ }^{15}$

Já a virada na Geografia Anglo-Saxônica se deu por volta do final dos anos 60 e início dos anos 70, tendo como referência no caso norte-americano, o núcleo organizativo gerado em volta da revista Antípode, fundada em 1969. A complexa situação política dos EUA teve seus efeitos potencializados entre os geógrafos americanos, pois já é nítida a consciência de crise do positivismo lógico e os primeiros conflitos pela busca de uma Geografia socialmente relevante já são visíveis no final dos anos $60 .{ }^{16}$ Ao analisar o desenvolvimento do que chamou de "um movimento radical dentro da Geografia nos E.U.A.", Peet identificou dentro deste um primeiro momento onde a característica marcante era uma visão ainda de caráter esquerda liberal, uma Geografia "mais relevante aos objetivos sociais, mas ainda presa a uma filosofia da ciência, a um conjunto de teoria, e a uma metodologia desenvolvida dentro de uma infra-estrutura existente das relações de poder". 17

Vendo dessa forma, não é de se estranhar que, já no início dos anos 70 , surjam os primeiros questionamentos a seu respeito no Brasil. Não à toa, apenas anos mais tarde, haveria uma percepção mais nítida desses eventos. Nesse momento da história brasileira, em termos de repercussão do marxismo no Brasil, podemos identificar os seguintes pontos:

1. A permanência de um marxismo de caráter ortodoxo na esquerda brasileira, em virtude dos setores hegemônicos advindos do PCB e outros grupos esquerdistas, onde as elaborações teóricas ainda são superficiais e com erros grosseiros de interpretação da teoria marxista;

2. Um contínuo crescimento de um marxismo que se desenvolve na academia de maneira mais sofisticada, canalizando-se mais especificamente em questões de teoria e método.

Temos, então, uma conjuntura na esquerda caracteriza por uma grande miscelânea de direcionamentos teóricos, desde linhas tradicionais do pensamento marxista (Lênin, Trotsky, Mao), até autores derivados do chamado marxismo ocidental (Lukács, Gramsci) e mesmo intelectuais preocupados com as análises econômicas do dito Terceiro Mundo (André Gunder Frank). Em meio a essa ligação intensa entre a visão marxista européia e o pensamento latino-americano, a filiação teórica de Althusser e seus discípulos destaca-se de tal maneira que, rapidamente, define-se hegemônica como nenhum outro no período. $^{18}$

Com isso, se por um lado, podemos caracterizar o Movimento de

TAMOIOS. ANO V. № 1, 2009 - ISSN 1980-4.490 
Renovação Crítica da Geografia, ou Geografia Crítica, como é popularmente chamado, de, majoritariamente, a ascensão da esquerda na comunidade geográfica, por outro as posições destes geógrafos dentro dessa mesma comunidade não são as mesmas, pois temos, dentro deste conjunto, desde professores de carreira acadêmica já estabelecida na academia, geógrafos em nível de graduação e pós-graduandos desenvolvendo suas atividades docentes e estudantes de graduação, estes últimos com ações que buscavam aliar formação científica com a militância política. Assim, o perfil pluralista desses intelectuais não permite configurá-los dentro de um bloco homogêneo de ação com um direcionamento político estreitamente delimitado.

Isso ratifica a análise de Silva sobre a produção geográfica do período entre o final da década de 70 e início de 80 , trabalhos estes feitos por aqueles membros da comunidade geográfica "então descontentes com a situação oficial de sua disciplina" (Silva: $83 / 84$, p. 73 ). O período pré-78 tem como destaque a mudança na linha editorial do Boletim Paulista de Geografia número 51 que, além de uma mudança na edição gráfica do periódico, também vem acompanhada por uma mudança na sua linha editorial. Durante as edições do número 51 ao 54 , encontram-se textos onde as cujas temáticas já apresentam grandes diferenças em meio à Geografia predominante. Entretanto, de acordo com as observações feitas pelo autor nessa fase, o andamento dessas publicações indicava apenas um mero momento de "modernização conservadora", pelo fato de que, "como não ocorria a ruptura política, a ruptura teórica descansava no leito da indiferença oficial".

Nessa direção, o impulso definitivo para a Renovação teria vindo, sobretudo, da militância de geógrafos na esquerda política, não havendo, assim, um "acesso à teoria marxista pela via acadêmica", desconectado o referencial marxista da geografia. ${ }^{19}$

O pensamento geográfico elaborado nos anos iniciais da Renovação tinha como grande nexo unificador, dentro das variantes encontradas entre seus autores, a necessidade de dar à Geografia a legitimidade de uma ciência social, ou seja, a defesa de uma concepção de Geografia focada na sociedade, nas suas dinâmicas, conflitos e contradições a partir dos fenômenos espaciais. Esse objetivo que, além de ratificar a posição dos geógrafos dentro das Ciências Humanas, também implicava num perfil de intelectual com certo nível de engajamento ante as questões sociais, teve como principal consequência, em termos teóricos, um aprofundamento nunca antes visto dentro da busca de um diálogo constante com a epistemologia, com a Teoria Crítica como um todo e, de maneira predominante, com o pensamento marxista. Haja vista este retrospecto, no que diz respeito às referências marxistas, o Movimento de Renovação apresenta correspondências com o próprio movimento da esquerda brasileira, na medida em que, em seus textos, podemos encontrar tanto representantes das variantes clássicas do pensamento marxista, quanto seus intérpretes associados ao marxismo ocidental.

As imprecisões na delimitação das diversas filiações marxistas até

TAMOIOS. ANO V. № 1, 2009 - ISSN 1980-4490 
hoje causam bastante confusão, principalmente com o uso do rótulo Geografia Crítica, diretamente associado à Geografia Marxista, como é o caso da definição feita por Diniz Filho, 2002, onde a identificação do marxismo como a linha filosófica dominante é colocada como critério de classificação. Dentro desse pressuposto, o autor identificou alguns pontos comuns desse diálogo teórico que, para ele, sintetizam as características principais da Geografia naquele momento e nos dias atuais:

\begin{abstract}
"a) no plano epistemológico, subsidiando os esforços de redefinição do objeto da disciplina, fornecendo um método de análise que se procurava aplicar a esse objeto e ainda um discurso que atribuía ao método marxista uma cientificidade inquestionável; b) no plano teórico, por oferecer uma teoria crítica ampla do capitalismo e um sistema de conceitos e teorias mais específicas passíveis de serem aplicadas no estudo de temas geográficos; $c$ ) na esfera ideológica, moldando (e ao mesmo tempo se amoldando) à "visão de mundo" dos geógrafos, isto é, as representações e valores simbólicos que orientam seus posicionamentos políticos; d) no plano deontológico, estabelecendo a existência de um estreito vínculo entre ciência, ética e política e enfatizando a necessidade da ação militante, a qual deveria tomar por base os pressupostos teóricos e metodológicos mencionados para assumir um caráter científico e socialmente transformador." (Diniz Filho, 2002: 83)
\end{abstract}

Aqui, acreditamos que tal confusão e generalização possam ser creditadas, entre outros motivos, ao fato da Renovação, ter permitido a criação de um "modismo" novo no discurso geográfico, com a presença de novos termos que são adequados à linguagem do geógrafo. Esse "modismo", associado com a multiplicidade de interpretações diferentes do marxismo dentro da Geografia, torna-se plausível como hipótese para justificar a falta de aprofundamento por parte da maioria da comunidade geográfica e a consequente leitura superficial do marxismo dentro da Geografia, ilustrando um movimento comum muito bem identificado por Saes.

"O amadurecimento da reflexão sobre qualquer corrente inovadora de pensamento jamais se processa instantaneamente; muito pelo contrário. Esse processo de amadurecimento intelectual ocupa não meses, e sim anos ou até mesmo décadas. Por essa razão, muitos dos trabalhos que repercutem imediatamente, de modo 'positivo' ou 'negativo', teses inovadoras tendem a uma 
certa superficialidade; e se configuram, numa certa medida, como expressões daquilo que a sociologia da cultura convencionou chamar 'modas intelectuais'. Ora, paralelamente à implantação e à estabilização (sempre efêmera) de uma nova moda intelectual - e inclusive após o esgotamento dessa moda - , processa-se, num círculo intelectual restrito, a assimilação profunda, em todas as suas implicações e mediações, das teses superficialmente convertidas em moda intelectual. Por 'assimilação profunda' entenda-se: capacidade de propor novos argumentos favoráveis a tais teses e de desenvolver teoricamente alguns dos seus aspectos; ou, inversamente, capacidade de criticá-las, expondo sistematicamente os seus desajustes internos e, no limite, contrapondo-lhes alguma alternativa teórica. (Saes, 1998:12)

A partir dessa crítica, entendemos que nos encontramos em um outro momento onde não apenas há a entrada de novos atores mas também novas referências de pensamento que, se não são de continuidade com o temário de marxismo, atestam a afirmação de uma linha onde a Teoria Crítica ganha força e se desenvolve, entretanto já com diferenças bem distintas desse período inicial. Nesse cenário, há a possibilidade de se estabelecer essa "assimilação profunda".

\section{Considerações Finais}

Os acúmulos gerados pela pesquisa que resultaram na redação desse texto apontaram, em um momento inicial, a necessidade de revisitar o pensamento dos geógrafos clássicos, especialmente no período anterior à chamada Geografia Ativa na França. A parca bibliografia encontrada revela uma interessante lacuna acerca dos possíveis interstícios envolvendo os geógrafos e o Marxismo e, a partir desse pressuposto, as conseqüências no campo teórico. Nesse sentido, cabem investigações mais específicas sobre a produção destes geógrafos com vistas ao destrinchamento de suas matrizes teóricas. O mesmo pode se dizer sobre as mudanças que ocorrem no campo científico dos geógrafos referentes a identificação de seus direcionamentos políticos, bem como dos discursos geográficos atrelados a estes e suas e suas conseqüências.

É fundamental o entendimento da Renovação como momento de ascensão da esquerda da comunidade geográfica, numa fértil situação da história brasileira que se desenhou no final dos anos 70 e início de 80, marcada 
pela abertura política. As especificações desse movimento e a maneira pela qual o marxismo se destacou como opção teórica-metodológica privilegiada não prescindem, em momento algum, às transformações que ocorriam na própria esquerda brasileira como um todo. Foi com base nesta diretriz que optamos por dialogar de maneira mais intensa pelos meandros da historia política do país, bem como do pensamento estruturalista na França.

No processo de intensificação do diálogo com o marxismo onde, dada a multiplicidade de pontos de vista políticos, também se verifica a mesma miscelânea de direcionamentos teóricos, seja na perspectivas clássicas do marxismo até suas vertentes mais ligadas ao mundo acadêmico, como o chamado "marxismo ocidental". Em meio a onda do estruturalismo francês, que se desdobra em sua versão marxista com a presença de Althusser na América Latina graças às versões "traduzidas" de seu pensamento a partir de seus alunos, sobretudo a inegável relevância de Martha Harnecker, esse marxismo estruturalista de segunda mão é largamente difundido tanto entre os círculos militantes quanto em determinados setores da esquerda acadêmica.

\section{Notas}

1- É sabido que os créditos para a invenção da palavra "marxismo" são dados aos anarquistas contemporâneos a Marx, que assim chamavam a ele e seus seguidores, "com propósitos desqualificadores, simplificadores ou mesmo persecutórios." Além disso, mesmo com Marx ainda vivo já apareciam as primeiras formas de simplificação e vulgarização de seu pensamento na forma de resumo e pequenos manuais: " $A$ esses 'catecismos revolucionários', formulados por amigos e colaboradores, também se atribuiu o nome de marxismo - apesar do protesto de Marx contra as simplificações abusivas" (Reis, 2007, pp 439-440)

2- Problema identificado há décadas atrás por Lukács em História e Consciência de Classe, de 1923 como uma relação de excludência, ou seja, a impossibilidade deste tipo de recorte dada a complexidade da obra de Marx, situada fora da compartimentação tipicamente positivista dos saberes (cf. Netto, 2004, p. 239). Quaini, 1979, p. 51 propôs como forma de se referir a este tipo de perspectiva o termo "adisciplinaridade".

3- De Martonne: 1953, p. 12

4- Conforme apontam Moraes: 1983 e Vitte: 2006.

5- Enquanto Ritter tinha uma postura extremamente conservadora, até por

TAMOIOS. ANO V. № 1, 2009 - ISSN 1980-4490 
ser monarquista, Hegel, embora não fosse exatamente de esquerda, tinha certas posições que se contrapunham aos círculos aristocráticos da época.

6- Quaini, 1979: p. 148.

7- Idem, p. 36. Sobre a perspectiva geográfica em Hegel ver Chatelet: 1989, pp. 45-62.

8- obre a difusão e a vulgarização do marxismo nesta época ver Andreucci: 1985.

9- Idem, ibidem, p. 108.

10- Santos: 2002, p. 51

11- Gostaríamos de deixar claro aqui que estamos nos detendo detidamente nas referências do pensamento geográfico francês, por constituir-se na matriz principal da Geografia Brasilera, conforme Moreira: 2008. Fica registrado, então, que não estamos considerando possíveis autores da Geografia Alemã onde pode-se verificar uma aproximação maior com o marxismo, como é o caso de Karl Wittfogel. Sobre esse autor ver Heidemann e Barbosa: 1992.

12- Bomfim, 2007, p. 98

13- Idem, ibidem.

14- Idem, PP. 100-101.

15- Lacoste, respectivamente 1974 e 2003.

16- Peet: 1982, p. 230.

17- Cf. Peet, 182, p.232.

18- Esse fato pode ser constatado através de um exercício empírico se atentarmos para o número de publicações de Althusser no Brasil, desde a primeira edição de Pour Marx (aqui publicada com o nome de Análise Crítica da Teoria Marxista), de 1964 até republicações de Ideologia e Aparelhos Ideológicos de Estado que remontam a década de 80, em comparação com obras de outros marxistas renomados como Gramsci e Lukács, de tiragem relativamente menores.

19- Gonçalves apud Scarim: 2000, 165-166. 


\section{Bibliografia}

ANDREUCCl, Franco. A Difusão e Vulgarização do Marxismo. In: HOBSBAWN, Eric (org.). História do Marxismo: O Marxismo da Época da Terceira Internacional. São Paulo, Paz e Terra: 1985.

BOMFIM, Paulo Roberto de Albuquerque. A Ostentação Estatística (um projeto geopolítico para o território nacional: Estado e planejamento no período pós-64) Tese de Doutorado. São Paulo, USP: 2007.

CHATÊLET, François. Hegel e Geografia. GEOSul, Florianópolis, EDUFSC:1989.

DE MARTONNE, Emmanuel. Tratado de Geografia Física in: Panorama da Geografia. Editora Cosmos, Lisboa: 1953.

DINIZ FILHO, Luis Lopes. Certa má herança marxista: elementos para repensar a Geografia Crítica. In: KOZEL, S.; MENDONÇA, F. (org.). Elementos de epistemologia da Geografia contemporânea. Curitiba, Ed. da UFPR, 2002.

HOBSBAWN, Eric J. A cultura européia e o marxismo entre o Séc. XIX e o Séc. XX. in: HOBSBAWN et al. (org.) História do Marxismo Vol 2. O Marxismo na época da Segunda Internacional. Rio de Janeiro, Paz e Terra: 1982.

LACOSTE, Yves. A Geografia, in: CHATELET, Francois (org.), História da Filosofia - Idéias, Doutrinas, vol 7 A Filosofia das Ciências Sociais - De 1860 a Nossos Dias. Rio de Janeiro, Editora Zahar: 1974.

A Geografia, isto serve, em primeiro lugar, para fazer a guerra. São Paulo, Editora Papirus: 2003.

MORAES, Antonio Carlos Robert. Alexander von Humboldt, Karl Ritter e Freidrich Ratzel Dissertação de Mestrado. São Paulo, USP: 1983.

MOREIRA, Ruy. O Pensamento Geográfico Brasileiro - As Matrizes Clássicas Originárias. São Paulo, Contexto: 2008.

NETTO, José Paulo. Marxismo Impenitente - Contribuição à história das idéias marxistas. São Paulo, Cortez: 2004.

PEET, Richard. O Desenvolvimento da Geografia Radical nos Estados 
Unidos in: CHRISTOFOLETTI, Antonio (org.) Perspectivas da Geografia. São Paulo, DIFEL: 1982.

QUAINI, Massimo. Marxismo e Geografia. Rio de Janeiro, Paz e Terra: 1979. REIS, Daniel Aarão. Marxismo, Sociedade e Partidos Políticos Hoje in: RIDENTI, Marcelo e REIS, Daniel Aarão (org.) História do Marxismo no Brasil Partidos e Movimentos após os anos 1960. Campinas, Editora da UNICAMP: 2007.

SAES, Décio. O Impacto da Teoria Althusseriana da História na Vida Intelectual Brasileira. in: MORAES, João Quartin de (org.). História do Marxismo no Brasil: Teorias. Interpretaçãoes vol. III. Campinas, Editora da UNICAMP: 1998.

SANTOS, Milton. Por uma Geografia Nova - Da Crítica da Geografia a uma Geografia Crítica. São Paulo, EDUSP: 2002.

SCARIM, Paulo Cesar. Coetâneos da Crítica - Uma Contribuição ao estdo do Movimento de Renovação Crítica da Geografia Brasileira. Dissertação de Mestrado. São Paulo, USP: 2000.

SILVA, Armando Corrêa da. De Quem é o Pedaço? São Paulo, Hucitec: 1986.

A Renovação Geográfica no Brasil - 19761983:

As Geografias Radical e Crítica na Perspectiva Teorética, in: Boletim Paulista de Geografia no 60. São Paulo, AGB São Paulo: 1983.

SOJA, Edward. W. Geografias Pós Modernas A Reafirmação do Espaço na Teoria Social Crítica. Rio de Janeiro, Jorge Zahar Editor: 1993.

VITTE, Antonio Carlos. Da Metafísica da Natureza à Gênese da Geografia Física Moderna in: VITTE, Antonio Carlos (org.). Contribuições à história e à epistemologia da Geografia. Rio de Janeiro, Bertrand Brasil: 2007. 